\title{
The Goal of Advertisement Translation: With Reference to C-E/E-C Advertisements
}

\author{
Ying Cui \\ City University of Hong Kong
}

\begin{abstract}
Advertisements have a clear goal to promote a product or service by appealing to the audience, so the conditions of target readers must be considered. Thus, there are various restrictions for advertising, including people's habits and customs, religion and beliefs, morals and ethics, laws in the target place, and linguistic or stylistic requirement. A translated advertisement is supposed to promote a product or service in the target culture. In this sense Skopos theory can be applied, for it pays great attention to purpose of translation, and holds that, as long as the purpose of translation can be realized, the translation is successful. Guided by this theory, we will summarize five points to be considered in advertisement translation. First, there is no need to stick to linguistic equivalence, for the dominant rule is the skopos rule. Second, the translated advertisements should be both textually and intertextually coherent in order that the readers can understand and trust them. Third, habits and customs, religion and beliefs, morals and ethics of the target audience should be considered and respected. Fourth, the relevant laws and regulations in the target culture should be observed. Fifth, the stylistic requirement of advertisements should be met.
\end{abstract}


8 The Goal of Advertisement Translation

Keywords: goal, advertising translation, skopos theory

\section{Introduction}

This paper attempts to dispose of the restrictions of traditional translation criteria on advertising translation, and apply skopos theory, which lays great emphasis on the goal of translation, to advertisement translation. Advertisements, designed with a practical purpose to promote a product or a service and make profit, are different from other text types, such as novels, poems or editorials, which are not so strictly purpose-oriented. Advertisement translations are also thus intended to promote a product or service in target culture. Therefore, traditional translation theories, which emphasize linguistic equivalence, pay a great deal of attention to the source text and hence somehow neglect the target readers and the purpose of translating, are not applicable in advertisement translation.

There have been studies exploring translation from the skopos perspective (See Duan Zili 2002; Guo Dongnv 2003; Jiang Haiqing 2002, Wang Jinquan 2000; Zheng Haiyan 2001). However, these are preliminary explorations into skopos theory, and several important notions in it have been left out. In our study, we are trying to do a systematic review on skopos theory and then explain advertisement translation as required by skopos. Guided by skopos theory, which stresses the aim or goal of translation and is in line with advertisements, we hereby propose five points that should be considered while transla-ting advertisements. In section one, the goal of advertisements and its realization are explained in detail, including the restrictions under which advertisements function. Section two will introduce skopos theory systematically, covering its development and its significance compared with traditional theories, focusing on Vermeer's views. In section three, under the direction of skopos theory, which provides only general instruction but no 
specific strategies, five points will be proposed that should be taken into consideration in advertisement translation and which will play an important role in realizing the goal of advertisement translation.

\section{The Goal of Advertisements and its Realization}

While an American is accustomed to using Fuji photo film in his camera, wearing clothes made in South Korea, and drives a Honda, a Malaysian smokes Marlboro cigarettes and uses a Dell computer, and a Brazilian drinks California wine, buys food in Wal-mart, eats Kentucky Fried Chicken and drinks Coca Cola. A decade earlier, these images might have been unimaginable. The economic competetion between different countries grows fiercer to gain the attention of people the world over. To stand out among the countless new products and technologies that mushroom throughout the world is difficult yet vital. One of the most workable ways is to advertise effectively. Thus, advertising plays an essential role in the modern economy, for however excellent a product is, it has to become known and recognized before consumers may tend to choose the particular brand. There are many ways of advertising and advertisements can be categorized with various standards. According to the ways of expression, there are advertisements that provide information, that leave an image in people's minds or appeal to feelings. According to the specific media, there are advertisements on handouts, on the TV or radio, on posters or on buses. According to the artistic modes, there are advertisements in the form of pictures, words, or performance. However classified, all advertisements can have a great influence on consumers by changing their notions concerning consumption and hence their behavior, on enterprises by promoting their products and services, and on the market economy by accelerating its development. Advertisements also play an important role in the progress of the mass media, literature and art, 
beautify the environment and enrich lives. In the next section, we will illustrate in detail the function of the advertising language with reference to the goal of advertising.

\subsection{The Goal of Advertisements}

According to Bühler, the main functions of language are the expressive, the informative and the vocative functions. The expressive function refers to what the speaker knows; the informative function means the outside world, the facts or ideas; and the vocative function is to appeal to the addressees, calling upon them to action (Newmark 2001: 39). Jakobson proposes three other functions, the aesthetic, the phatic and the metalingual. The aesthetic function aims to please the senses, the phatic function is to maintain cordial relationships, and the metalingual function means that language can talk about itself (Newmark 2001: 39-44). The language of advertisements is mainly intended to be vocative, appealing to the readers with the goal of having them buy a product or a service. Meanwhile, the language of advertisements is also informative and has aesthetic value. According to the communicative functions of language, Reiss classifies three kinds of text types, namely informative texts, expressive texts and operative texts. Informative texts aim to provide information, expressive texts focus on the stylistic beauty, and operative texts aim to achieve some extralinguistic effect (Nord 2001: 37-38). It is obvious that advertisements are operative texts, which are mainly intended to persuade the readers to spend money on a product or service. To put in another way, advertising is a kind of "paid non-personal communication from an identified sponsor using mass media to persuade or influence an audience" (Wells 1999: 13). Advertisements aim to produce an effect in consumers that will arouse in the desire to buy or do something, so as to promote a product or service and make profit in the end. 


\subsection{Realization of the Goal}

"Modern advertising is led by objects and implemented through carefully designed strategies" (Wells 1999: 13). In order to realize their goals of promoting a product or service, advertisements are usually designed to be creative and original, and thus endowed with stopping power, pulling power and locking power. These powers work in such an order as "perception-awareness-understandingpersuasion-memorability" (ibid.). In other words, an advertisement should have enough stopping power to make the audience aware of the advertisement when they see or hear it. This is done by various artistic and stylistic means such as a surprising picture, unconventional diction or tantalizing questions. An advertisement should also have the pulling power so that the audience can be attracted and persuaded after understanding it. They should be convinced by the advertisement that the product or service advertised is good and worth spending money on. This can be achieved by providing useful information or close reasoning. The advertisement has to be true and reliable. Finally, an advertisement should be able to exert the locking power to help the audience remember it, so that the final aim of promotion can be realized. ${ }^{1}$ Thus, it is usually short and sounds sweet, with a special charm of its own, employing advantages of different media and fully grasping the audience's psychology. In one word, advertisements function by appealing to the audience to realize their goal. Having clarified how advertising works under general circumstances, in the next section we will illustrate some restrictions for the operation of advertising including the translation of advertising texts.

\footnotetext{
See Wells 1999: 245-258.
} 


\subsection{Restrictions under which the Goal Is Realized}

Advertisements have a goal of persuading people to accept and buy a product or a service. Guided by this specific purpose, advertisements resort to various strategies to draw people's attention. In order to be accepted by the audience, their specific conditions have to be taken into account. There are several restrictions for an advertisement to function, especially for one produced in one place to function in another, as is the case of advertising translation. Since advertisements are intended to be accepted by the audience to function, they have to be attractive and appealing in style. The target readers' habits and customs, religion and beliefs, morals and ethics should all be respected. Besides, the relevant laws and regulations in the target countries should be observed.

Advertisements are composed of verbal and nonverbal parts, and it is usually the verbal part that is translated. The title of an advertisement typically should be concise and precise, memorable and eye-catching, creative and original, foregrounding the essence of the message. As a rule, the text of an advertisement is supposed to be interesting and appealing, never tedious and superfluous. The slogan of an advertisement is expected to be short, melodious and easy to remember. The advertisements on TV need not be that detailed and complete, for the pictures and sounds can help the audience understand it (Ni 2001: 153-173). The fulfillment of these requirements can help advertisements function well. Otherwise, it might be difficult for them to be accepted as advertisements, and the goal would be hardly attained. After all, nobody would be interested in an advertisement that is as long and boring as an obscure editorial in a newspaper.

Habits and customs play an important role in designing an advertisement. Chrysanthemum, the national flower of Italy, is used only in funerals in some Latin American countries, for the flower is considered to be evil by the people there. Rose and lily are symbols 
of love and friendship in many countries, but they are used to mourn the dead in India and some European countries. So they can never be used as decoration or a brand-mark. Yellow flowers imply disloyalty in France, and purple flowers are for funerals in Brazil (Miao 1994: 298). Canadians and Americans love animals and are disgusted at the thought of a pet being eaten. In Burmese and Indians never pass things or serve with their left hands (Zhuang Enping 1998: 101). Therefore, much attention should be paid to make sure that the advertisement does not hurt or offend the people for whom it is intended.

Religion should not be taken for granted in order that an advertisement can be accepted and effective in promotion. Cattle are holy animals in India where Buddhism is popular, but people in the Middle East, who mainly believe in Islam, eat beef as an indispensable food. Most Protestants pay much attention to sanitation and hygiene, and therefore use perfumed soaps in baths. In contrast, Catholics consider it sinful to revel in bathing and dressing. Thus in France, where Catholicism prevails, most women Catholics use laundry soaps in baths. In some areas, people do not accept products that can save labor or make life easier and more comfortable, for they are instructed by their religion to be austere and hard-working (Miao Jie 1994: 298). Therefore, advertisements should respect people's beliefs so as to be accepted and realize their final goal to promote a product or a service. Otherwise, if advertisements offend their audience who are strongly influenced by their religion, there would be no chance of promotion or making profit.

Morals and ethics should also be taken into consideration. An advertisement is supposed to be decent for its audience. Ogilvy and Mather once said: "Never run an advertisement you would not your family to see" (Wells 1999: 73). In China, people are strongly influenced by Confucianism and even now the sense of propriety still works. They are usually a bit conservative; they consider modesty as a great merit; they value the interests of others or a 
group as a whole, and they consider it moral and honorable to sacrifice self interests for others. However, in the West, individuality is given more emphasis and people there are more open-minded in their behavior. They usually pay more attention to one's own likes and dislikes, and regard this as perfectly natural. And perhaps modesty may be considered as insincere in some cases. Therefore, these different notions in different cultural background should not be neglected in advertising.

Advertisements are controlled by various laws and regulations in the intended local places. In China, an advertisement shall not use the national flag, the national emblem, the national anthem, the names of state organs or their functionaries. No such terms as 'statelevel,' the 'highest-grade,' or 'the best' shall be employed in an advertisement and at the same time, commodities or the services of other producers and dealers shall not be belittled. Furthermore, the mass media shall not present an advertisement in a news report format (Ni 2000: 326-332). In the United States, according to the courtesy of the American Advertising Federation, bait advertising cannot deliberately lead consumers to buy more expensive goods, guarantees and warranties should be explicit and contain sufficient information, false or misleading price claims should be avoided; and good taste and public decency should be respected (Wells 1999: 4649). Comparative advertisements are not allowed in China, but they are legal in America (Miao Jie 1994: 60). The Federal Trade Commission supports comparative advertising as a way of providing more information. American Association of Advertising provides guidelines for comparative advertising: the intent should be to inform, not to discredit or unfairly attack; the competition should be identified, fair and proper; and comparison should be made between similar properties and ingredients (Wells 1999: 65). Advertising also has its own self-regulation. Take media as an example. Reader's Digest refuses tobacco and liquor advertisements (Wells 1999: 72). In Japan, a TV advertisement should not be longer than 15 seconds 
(Miao Jie 1994: 305). Therefore, the laws and regulations should be observed so that an advertisement can function well in the target regions.

\section{Skopos Theory Revisited}

In the previous section, we have explained the function of adverti-sing language, the realization of such function, and the restrictions under which advertisements are run. All these are talked about with reference to the goal of advertising. In this section, we will introduce the skopos theory which focuses on the goal or purpose of doing things including translation, in the hope that the theory can explain and inspire the translation of advertisements.

"The 1970s and 1980s saw a move away from the static linguistic typologies of translation shifts and the emergence and flourishing in Germany of a functionalist and communicative approach to the analysis of translation" (Munday 2001: 73). In the German functionalist school, there is skopos theory which pays uttermost attention to the goal of translation. In the light of this point, it is relevant to the translation of advertisements which are strictly operative in terms of their final aim- promoting a product or service and making profit in the end. Reiss moves translation theory from lower linguistic levels to the communicative purpose of translation. Basing her theory on the concept of equivalence, Reiss borrows Karl Bühler's categorization of the functions of language, and links the three functions to their corresponding language dimensions and to the text types or communicative situations in which they are used. She also summarizes features of informative, expressive, operative and audio-medial text types (Munday 2001: 73-76). Hans Vermeer further develops skopos theory. He considers translation as a human action which is intentional and purposeful. The aim or purpose of translation is thus called 'skopos.' It is the skopos that determines 
specific translation strategies and methods that are applied in order to produce functionally adequate results. Skopos theory focuses all on skopos, not paying as much attention and respect to source text (ST) as traditional theories do (Nord 2000: 10-12; Munday 2001: 78-81).

Justa Holz-Mänttäri proposes a translational action model, which places translation within the social and cultural context and includes the interaction between the translator and the initiating institution. Mänttäri adopts the term "message transmitter" to refer to textual material and other media. She stresses the analysis of the participants (initiator, translator, user, and message receiver) and the situational conditions (time, place and medium) of the translational action (Nord 2000: 12-13; Munday 2001: 77-78). Christiane Nord finds that skopos rule could mean that translators are free to do whatever they like and in putting this to right, she introduces loyalty to the functional model. Loyalty refers to translator's responsibility towards their partners in the translational interaction, taking into account the interests of initiators, target receivers and original authors. Thus, skopos theory is turned anti-universal, for the difference between culture-specific concepts of translation is considered; and as a result the radical functionalism is less prescriptive, for the translator is encouraged to repeat the sender's intention. Nord also provided a new model of ST analysis, bringing together functional and actional theories (Nord 2000: 123-128; Munday 2001: 81-84). So far we have illustrated the developmental line of the theory, and next we will look into the content of this theory.

According to Vermeer, "the skopos theory is a theory of translational action" (Venuti 2000: 221). In his definition, an action must have an aim to be called an action: "For an action of behavior to be called an action the person performing it must (potentially) be able to explain why he acts as he does although he could have acted otherwise" (Nord 2000: 19). Here, action and behavior are distinguished. Behavior can be with a purpose, to illustrate, writing a business 
letter, or without a purpose, like sleep-walking. And only the former, namely the behavior with a purpose can be regarded as an action. Otherwise, the behavior without a purpose can only be behavior (ibid: 15-26). In Vermeer's views, translation is an action, to which at least three kinds of purposes can be attributed. First, there is the general aim of the translator to do the translation. For example, he or she might want to make a living. Second, there is the purpose of the target text, perhaps to offer some information or give instruction. Third, there is the purpose of a particular translation strategy or procedure. For example, to translate literally is in an effort of showing the linguistic peculiarities of the source language (SL). In the 1970s, Vermeer introduced the term "skopos" from Greek to refer to the aim of translation, or rather the purpose of the target text (TT) (ibid: 27-28). Therefore, in skopos theory, translation is treated as an action which has a purpose, and it is the purpose, namely skopos, that should be particularly considered in the process of translation. The special attention paid to the purpose of translation is the most distinctive feature of skopos theory. In the following subsections, we will introduce several important notions in skopos theory, including the rules, commission, and role of translators in the theory.

In "Groundwork for a General Theory of Translation" written by Reiss and Vermeer in 1984, a detailed explanation of skopos theory is provided. The basic rules include: (1) a translation (or TT) is determined by its skopos; (2) a TT is an offer of information in a target culture and TL concerning an offer of information in a source culture and SL; (3) a TT does not initiate an offer of information in a clearly reversible way; (4) a TT must be internally coherent; (5) a TT must be coherent with the ST; (6) and the five rules above stand in hierarchical order, with the skopos rule predominating (Munday 2001: 78-79). Since the skopos rule dominates, determining whether ST needs to be translated, paraphrased or completely rewritten, intertextual coherence and intratextual coherence should be 
subordinate to it. When a change of function needs to be attained in TT according to the skopos, intertextual coherence and intratextual coherence are no longer valid. As to the relationship between intertextual and intratextual coherence, Vermeer considers the former to be subordinate to the latter. He also believes that the concept of skopos can be applied in both entire text and text segments, such as footnotes or citations. The sub-skopos of those smaller units may differ from that of the entire text or other subunits (Nord 2001: 27-33; Munday 2001: 78-80; Venuti 2000: 231).

A careful look at the three important rules may show that in skopos theory the only rule that really count and can have the final say is the skopos rule. Though intertextual coherence and intratextual coherence are also mentioned and translators are encouraged to observe them, they are also intended to serve the skopos. Intertextual coherence can make the readers trust in the translator, and the trust is very important for the translated texts to be accepted, as is the first step to realize the skopos. Intratextual coherence can make the readers understand the translated texts more easily and accurately, as is also an important step for the skopos to be realized. So both intertextual coherence and intratextual coherence are intended to serve the skopos rule, they are always subordinate. As mentioned in the above paragraph, when the purpose or function in the ST is changed in the TT, intertextual coherence and intratextual coherence may not be observed. For instance, there is a coherent English text about the beautiful scenery in America to be translated into Chinese. The purpose of the ST is to entertain the audience and provide some information meanwhile. However, if the Chinese version is to show the peculiarities of the English language, the intertextual coherence and intratextual coherence are no longer valid. The ST may be translated word for word, which may make the Chinese version awkward to read. Therefore, the TT is not intratextually coherent, and thus there is no possibility of intertextual coherence. And all this is determined by the skopos. 


\subsection{Commission in Translation}

For Vermeer, "every translation is based on a commission" (Venuti 2000: 229), and a commission is "the instruction, given by oneself or by someone else, to carry out a given action-here, to translate" (ibid.). Usually the commission is apparent as to the purpose or addressees. For example, in our culture, a poem is supposed to be translated into a poem for those who are able to appreciate it. A commission comprises the goal and the conditions under which it should be attained. Since the client may have a false picture in terms of the way of a TT is received in a target culture, the translator needs to negotiate with him about the goal and the relevant conditions. Whether a commission can be realized or not is determined by the circumstances of the target culture. Therefore, the translator should decide in a specific situation whether he should accept the client's commission or not, what are the circumstances, and whether the commission needs to be modified according to the actual conditions. In one word, every translation can and must be assigned a skopos, which is decided by the commission and adjusted by the translator if necessary (Venuti 2000: 221-232; Nord 2000: 27-31). In other words, the skopos and the conditions under which it is realized, namely the circumstances in the target context, comprise the commission.

Though skopos is given the uttermost attention in skopos theory, the conditions cannot be neglected, for it would be impossible to attain the goal if the conditions are not taken into account. Since there is much difference between the source culture and target culture, the client in one culture who has assigned a translation task might not quite understand the elements in the other culture. Thus he might give the translator an impossible goal to realize. In this case, the translator should keep his own objective opinion instead of compromising himself to the client all the time. He should be able to give workable advice as to the commission. 


\subsection{The Role of the Translator}

Vermeer specifies the translator's task in detail. The translator, as a receiver of both translation brief, namely the commissioner's instructions and ST, should analyze whether the translation brief is acceptable in legal, economic or ideological terms and decide whether the translation is really necessary and useful. After that, he should specify the activities that are required to carry out the brief and then perform the translational action, which may result in a target text, "perhaps a short summary of the ST or, in special cases, in advising the client not to have the ST translated because a translation would not serve the intended purpose" (Nord 2000: 29). Therefore, under the guidance of skopos theory, the translator does much more than just translating the linguistic forms. He is supposed to make a careful assessment of the translating task, taking into consideration all the cultural conditions in the target text, to see whether or not it is worthwhile and legal.

What he does next is still not translating word for word. Instead, he is to translate in the most economical way, for it is enough to achieve the skopos. Thus he may employ many strategies, and he is fully justified not to be strictly faithful to the ST. An example given by Nord may illustrate the translator's task. In Jakarta, if one asks a policeman the way to a place, he will always give a detailed description as to how to get the very place, even if he does not know the way at all. Since he does not want to lose face, he will never say sorry (Nord 2000: 1-3). So in such a case, however long the policeman's reply is, it is enough for the translator to tell the person who is asking the way that "He does not know the way. Let us ask someone else." It does not make much sense to translate faithfully the policeman's description. Here, the translator is expected to be very familiar with the culture. 


\subsection{The Significance of Skopos Theory}

As a result of skopos theory, the ST is no longer regarded as the decisive factor and the translator has got his status as an expert. The theory makes explicit and conscious something that is often neglected or even denied, namely that one translates according to a specific purpose and there must always be a clearly defined goal. The skopos ensures the variety of translation, for different ways of translation can be justified as long as they can realize the purpose. As a result, it increases the range of possible translation strategies. And thus the translator is released from the meaningless restriction and requirement of literalness. It also makes accountable many of the translator's choices which would seem unacceptable according to the traditional criteria (Venuti 2000: 221-232). Therefore, skopos theory is significant in that it differs from the traditional theories in two points. First, it does not pay much attention and respect to the ST and the ST author. Instead, it values the skopos in the TT a lot. As a result, translation can be released from the restriction of the ST, including its linguistic forms or cultural implications. Thus the same ST can have varied translations for different purposes. Second, the translator is given more power and a higher status. Under the guidance of skopos theory, the translator has the right to decide whether it is necessary or not to translate a text, and he is justified to use different strategies. In other words, skopos theory gives us a fresh perspective to look at translation.

\section{Skopos and Advertising Translation}

The goal of this paper is to discuss the application of skopos theory in the translation of advertisements and summarize several points in advertising translation, which are often ignored. Thus, the awareness of the translator engaged in advertising translation can be 
raised, and the advertisement translations can be more effective in realizing their goals. Advertisements are designed for the sole purpose of promoting a product or a service. Though some of them provide information or possess aesthetic value, they also aim to get people persuaded and promote the product or service in question in the end. It may be justified to say that an advertisement is meaningless if it cannot help spread a concept or make profit. Since skopos theory emphasizes that the goal must be the central guidance for an action, it is in line with advertisements. Therefore, skopos theory is the "special theory" called for in the advertisement translation.

\subsection{Commission in Advertisement Translation}

To get an advertisement translated is to let people in the target culture understand the advertisement, become interested in the advertised product or service and finally spend money on it. Thus the skopos in the translation of advertisements is the same with that of advertisements, namely to promote a product or a service and make profit in the end. The difference lies in that a translated advertisement is intended for a different audience, a different culture and a different situation. Thus, all the factors in the target context should be considered, for they would determine whether the skopos could be realized or not.

While an advertisement is intended for a certain audience within the source culture and situational conditions, its translation is for different addressees who are influenced by their own culture and under different situational conditions, such as the time and place, the addressees' world knowledge, experience and expectations, and even the laws and regulations in the target country. Therefore, all these conditions should be taken into account in order that the skopos to promote a product or a service in the target culture can be realized. In advertising translation, the conditions include the special 
stylistic requirements of advertisements, the target readers' habits and customs, religious beliefs, moral values, and various laws and regulations in the target country concerning advertisements.

The translator is responsible for the function of a translated advertisement in the target culture. Whether his translation is successful or not depends on whether the translated advertisement can promote a product or not, that is, whether the skopos can be realized or not. Since the producer of an advertisement or the client who gives the commission of translating an advertisement may not know much about the target audience and the target culture, the translator must negotiate with the client to adjust the advertisement to the target addressees so that it can be accepted and realize its goal of promotion. Thus, the translator has to do much more than translating the words of the advertisement. Instead, he is also expected to give advice to the client, such as whether it is lawful or profitable or not, or even rewrite the advertisement according to the target culture if necessary. In advertising translation, the translator acts as more than a translator, and he is an advisor, a writer and a translator at the same time. He should not be restricted to the original advertisements, and should be given more initiative in advertising translation.

\subsection{Application of Skopos Theory}

Considering the skopos in advertising translation, there is no need to stick to linguistic equivalence or accuracy. This does not imply that in the process of translation an advertisement can be changed at will, but that to change the diction of the original advertisement is a possibility the translator can opt for, in his efforts to make the translation function effectively in promoting a product and making profit. When the main function of an advertisement is to provide information and its aim is to persuade the audience by logic, it is usually necessary to keep strictly to the ST and translate 
faithfully and accurately, retaining the diction if possible. But if the target addressees are children who cannot understand the information, the main function of the translated advertisement should no longer be informative, or persuasive by logic. In that case, the advertisement may be changed to be easier and more interesting so that children can understand and remember it. To be informative is only one possibility, and many advertisements are intended to appeal to the emotion of consumers to call on them to action.

Besides the skopos rule, intratextual and intertextual coherence should also be given due attention. This can also help attain the skopos in advertising translation. Otherwise, if the target readers cannot understand a translated advertisement or the translation goes too far away from the original text and facts, the skopos to have the advertisement function in the target culture can never be realized. Therefore, the way of expression in the translated text should be in keeping with the habits and rules of the target language.

The translated advertisement is intended for the target audience, so their habits and customs, likes and dislikes, and even religion and psychology should all be considered in the process of translation. In order to be accepted, an advertisement should not hurt the addressees' feelings or arouse their aversion. Since an advertisement is usually written for the readers in the source culture, sometimes it may offend the target readers if translated literally, though the original text may function well in the source culture.

A translated advertisement shall observe the laws and regulations in the target country, otherwise it cannot be publicized at all. If a client wants to run advertisements about cigarettes and spirits on TV in America, the translator can advise him not to have the advertisement translated, for it is not allowed to advertise those commodities on TV in America. If a long advertisement is to be translated into Japanese and broadcast on $\mathrm{TV}$, the translator may negotiate with the client to rewrite the advertisement into a shorter one, for in Japan a TV advertisement cannot exceed 15 seconds. In 
England, the name of a place cannot appear in a brand. In Germany and France, trademarks should not use words like "diet". In our country, advertisements shall not refer to information that suggests pornography, superstition, terror, violence, or hideousness, or engages in ethnic, racial, religious, or sexual discrimination. And there are particular laws for such products as drugs, medical equipment, cigarettes and spirits. When translating advertisements of these products, the translator may first of all make sure that the advertisement to be translated does not go against the law. When it does, he may give advice to the client or refuse to translate.

The stylistic features should also be taken into account during the process of translation. If a translated advertisement does not have the qualities of an advertisement, but seems like a news report or an essay, it will pose an obstacle for the audience to accept the advertisement translation. Thus the stylistic features of advertisements are also part of the commission. If the skopos is to be realized, the translated advertisement should have the typical features of an advertisement. Even if this requirement is not made explicitly, it is implied in the client's commission and entailed by the skopos.

\subsection{Case Study}

To illustrate what is concerned in this paper, the following Chinese advertisement and English translation ${ }^{2}$ will be analyzed in details:

\section{国氏全营养素 \\ 科学减肥新概念}

“国氏全营养素”把调节脂肪代谢,补充全面营养的独到理 论应用于控制体重,一时达到拥有苗条身材,保持充沛精

2 Cited from Luo Le. 2000: 59. 
力。相信曾被肥胖困扰的你,因为服用了全新口味的“国 氏全营养素, 不久也能体态轻盈, 充满活力。

“国氏全营养素”是著名营养学家国敏元教授从中国传统 调养理论出发,针对多数肥胖者的基本成因, 以调节体内 营养平衡,改变脂肪代谢能力为目的,精心配制的富含蛋 白质, 维生素, 多种氨基酸及微量元素的全天然、全营养 食品, 充分调动体内多种酶的活性, 迅速分解体内多余脂 肪, 使体态恢复健康苗条。

国氏理论以其科学性, 实效性在减肥领域开创了一条新 路，“国氏全营养素”被中国女子体操队指定为控制体重 营养品。减肥的同时, 轻松愉快, 精力充沛, 体重正常之 后，不会轻易反弹。所以，更多的体操运动员都钟情于 “国氏全营养素”。

京卫食宣字（95）0065 号

邮购地址：北京西直门内大街 32 号 格林沃德公司销售 部收

价格: 98 元/盒（含邮资）

邮购查询电话: 0100-6181372

中国女子体操队指定 控制体重营养品

中美合资格林沃德营养保健品有限公司

地址: 北京西直门内大街 35 号北展宾馆西八楼

销售联系电话: 010-83503138350323 电传：010-8350289

Guo Shi Quan Ying Yang Su

Ke xue jian fei xin gai nian

"Guo shi quan ying yang su” ba tiao jie zhi fang dai xie, bu chong quan mian ying yang de du dao li lun ying yong yu kong zhi ti zhong, yi shi da dao yong you miao tiao shen cai, bao chi chong pei jing li. Xiang xin ceng bei fei pang kun 
rao de ni, yin wei fu yong le quan xin kou wei de "guo shi quan ying yang su”, bu jiu ye neng ti tai qing ying, chong man huo li.

"Guo shi quan ying yang su" shi zhu ming ying yang xue jia guo min yuan jiao shou cong zhong guo chuan tong tiao yang li lun chu fa, zhen dui duo shu fei pang zhe de ji ben cheng yin, yi tiao jie ti nei ying yang ping heng, gai bian zhi fang dai xie neng li wei mu di, jing xin pei zhi de fu han dan bai zhi, wei sheng su, duo zhong an ji suan ji wei liang yuan su de quan tian ran, quan ying yang shi pin, chong fen diao dong ti nei duo zhong mei de huo xing, xun su fen jie ti nei duo yu zhi fang, shi ti tai hui fu jian kang miao tiao.

Guo shi li lun yi qi ke xue xing, shi xiao xing zai jian fei ling yu kai chuang le yi tiao xin lu, "guo shi quan ying yang su" bei zhong guo nv zi ti cao dui zhi ding wei kong zhi ti zhong ying yang pin. Jian fei de tong shi, qing song yu kua, jing li chong pei, ti zhong zheng chang zhi hou, bu hui qing yi fan tan. Suo yi, geng duo de ti cao yun dong yuan dou zhong qing yu "guo shi quan ying yang su".

Jing wei shi xuan zi (95)0065 hao

You gou di zhi: bei jing xi zhi men nei da jie 32 hao gel in wo de gongsi xiao shou bu shou

Jia ge: 98 yuan/he (han you zi)

You gou cha xun dian hua: 0100-6181372

Zhong guo nv zi ti cao dui zhi ding kong zhi ti zhong ying yang pin

Zhong mei he zi gel in wo de ying yang bao jian pin you xian gong si

Di zhi: bei jing xi zhi men nei da jie 35hao bei zhan bin guan xi ba lou

Xiao shou lian xi dian hua

010-8350313 8350323 fax :010-8350289 
28 The Goal of Advertisement Translation

\section{Lose $5 \mathrm{~kg}$ in 10 days!}

This is not magic.

It's Dr. Guo's Healthy-Slim Extract.

Yes, it's only natural.

Dr. Guo's Healthy-Slim Extract is not a medicine, but a completely natural food. It is rich in various nutrients that are especially important to dieters, including proteins, vitamins, amino acids and trace elements. Take it as dietary supplement to your dieting program-it's natural and safe.

Yes, it's indeed effective.

Dr. Guo's Healthy-Slim Extract helps you start and maintain a successful weight-loss program. It burns out fat, keeps you energized, and you don't have to suffer at all. Wouldn't it be great if you can keep fit and keep slim at the same time? Actually, you can! Because you have Dr. Guo's! Thousands of women have benefited from it, and it has been selected as the authorized weight-control food of the Woman's Gymnastic Team of China. So why should you wait for miracles to happen?

Just let Dr. Guo's to work out the magic on you!

The title “国氏全营养素 科学减肥新概念 (guo shi quan ying yang su, ke xue jian fei xin gai nian)" shows clearly that the advertisement concerns something that can help control the weight in a new and effective way. The first paragraph mainly explains the function of the extract, and two points are made here: losing weight and keeping energetic. The second paragraph was written in an effort to persuade readers to trust the product by presenting the traditional theories in China concerning nutrition, listing the nutritious elements that are good to people's health and explaining how the extract works. The third paragraph is intended to appeal readers by emphasizing the effect of the extract and the fact that it has won the favor of the Woman's Gymnastic Team of China. The 
rest of the advertisement provides some information about the purchase or manufacturer of the product. To sum up, the goal of this advertisement is to talk people into buying the extract, and it is realized by resorting to science and authority, for the nutritious theories, different nutritious elements, Dr. Guo and the Woman's Gymnastic Team of China are all mentioned to serve as some kind of proof for the product's quality.

The goal of the client to commission the translation task is to have the translated advertisement accepted by foreign readers in the foreign culture, and thus to promote the product. Firstly, the Chinese readers respect and trust science, and believe in authority, though they may not understand the nutritious theories or have any interest in learning the biological terms, namely those nutritious elements. The English-speaking people are not interested in the nutritious theories or elements either, but what they care about is not science or authority, but the effect and safety of the product. Secondly, the English-speaking people are very much concerned about their weight, and they hate to be considered obese. That is why they often keep their weight secret, and it is even considered as a taboo in conversation. Comparatively speaking, there is not so much sensibility among Chinese, though they also care about their weight. Actually, to say that somebody is fatter is regarded as a kind of compliment. Thirdly, the original advertisement is a bit long and somewhat tedious, as is against the style of advertisements. If it is translated literally, it will be too over-stuffed and boring to attract any readers.

The original author intends to realize the goal of promoting the extract by means of employing scientific facts and authoritative effects. However, this would not do for the English-speaking people who are more concerned about the effect and safety of the product. Therefore, the translator is supposed to adjust the way to realize the goal, giving priority to appeal over logical reasoning. 
The translation is not fettered by the original advertisement, either linguistically or culturally. The translator makes several adjustments which make the translation successful. First, an eyecatching sentence "Lose $5 \mathrm{~kg}$ in 10 days!" is put at the top of the advertisement in bold letters. This will certainly arouse the target readers' curiosity and interest, which will impact them to read the rest of the advertisement. Second, several sentences are added to the translation, such as "Yes, it's only natural.", "Yes, it's indeed effective.", "So why should you wait for miracles to happen?" and "Just let Dr. Guo's to work out the magic on you!". This makes the translated advertisement more personal and appealing, other than only coldly scientific. In this way, the translation will be more effective. Third, the taboo of "obesity" is avoided. The name of the product is perfectly translated as "Dr. Guo's Healthy-Slim Extract". Though it is not the literal translation of “国氏全营养素(guo shi quan ying yang su)", the implications needed are all included, namely "healthy" and "slim". Besides, the translator chooses the word "slim", which shows respect to the target readers' feelings. If “减肥 (jian fei, losing fat)” is translated as “obesity-reducing”, the target readers will be offended. For the same reason, the sentence “相信曾被肥胖困扰的你,因为服用了全新口味的“国氏全营养素, 不久也能体态轻盈, 充满活力 (we believe that you, who are troubled with obesity, after using this extract, will become slim and energetic soon.)" is not translated at all, otherwise the target readers will be very, very unhappy. Fourth, the nutritious theories are omitted in the translation. Thus, the translated advertisement is concise and effective.

Even if the theories are translated, it will not make much difference, for the English-speaking readers cannot understand the meaning at all. Since the translation is to appeal to the target readers, it should not be tedious or obscure. Fifth, while the two points, namely losing weight and keeping healthy, are not made so clear in the original advertisement, there being too much extra information, 
they are put clear in the translation. The target readers are repeatedly assured that the extract will be safe and effective. "Dr. Guo's Healthy-Slim Extract is not a medicine, but a completely natural food.", "Take it as dietary supplement to your dieting program-it's natural and safe.", "you don't have to suffer at all", and "keep fit and keep slim at the same time". Therefore, the translation of the advertisement is not the equivalent of the original one, for the translator has made several adjustments according to the skopos, paying much attention to the target readers. The final version will be more effective than a literal, word-for-word translation, for it has taken into consideration the conditions under which target readers receive the advertisement.

\section{Conclusion}

Advertisements are run to promote a product or a service and make profit in the end. This is done by appealing the audience. Guided by their clear goals, advertisements have to consider many constraints in order to function well, especially in another country. The constraints include the target addressees' habits and customs, likes and dislikes, religion and psychology, and the relevant laws and regulations in the target country. Skopos theory foregrounds the purpose of translation and pay great attention to target readers and their conditions, so it can be applied in the translation of advertisements. Guided by this theory, the authoress of this paper analyzes the commission in advertising translation: the skopos, namely the purpose of translation, is to get an advertisement accepted in the target culture and promote a product or service there; the conditions under which the skopos is realized cover the above mentioned constraints. Since skopos theory provides no specific strategies and only gives instruction to the translator, this paper does not aim to propose specific techniques in advertising translation. Instead, the flexibility and care of the translator is emphasized and 
valued. In other words, as long as the skopos of advertising translation can be realized, the translator is justified to use any strategies, some of which may not pay great attention to the ST, and has to take into account the specific constraints concerning advertising translation.

\section{References}

Baker, M. 1998. Routledge Encyclopedia of Translation Studies. London \&New York: Routledge.

Munday, J. 2001. Introducing Translation Studies: Theories and Applications. London \&New York: Routledge.

Newmark. P. 2001. Textbook of Translation. Shanghai: Shanghai Foreign Language Education Press.

Nord, C. 2001. Translation as a Purposeful Activity: Functionalist Approaches Explained. Shanghai: Shanghai Foreign Language Education Press.

Venuti, L. 2001. The Translation Studies Reader. London \&New York: Routledge.

Wells, W. et al. 1999. Advertising-Principle and Practice(Fourth edition). Beijing: Qinghua University Press.

Duan, Z. 2002. An Introduction to and Comment on Skopos Theory [翻译目的论介评.渝州大学学报(社会科学版)]. Joural of Yuzhou Universty 2, 81-84.

Guo, D. 2003. The Translation of Culture from the Point of Skopos Theory [从目的论看文化因素的翻译.河北理工学院学报]. Journal of Hebei Institute of Technology (Social Science Edition) 2, 114-116.

Jiang, H. 2002. Skopos Theory in Translation Studies [浅谈翻译目 的论. 盐城师范学院学报 (人文社会科学版)]. Journal of Yancheng Teachers College 3, 87-89.

Luo, L. 2000. Strategies and Techniques in Translating Chinese 
Advertisements into English [汉英广告翻译的策略与方法. 南 都学坛(哲学社会科学版)]. Academic Forum of Nan Du 3.2, 58-60.

Miao, J. 1994. Modern Advertising [现代广告学.北京: 中国人民大 学出版社]. Beijing: China Renmin University Press.

Ni, N. 2004. Advertising Textbook [广告学教程. 北京:中国人民大 学出版社]. Beijing: China Renmin University Press.

Wang, J. 2000. Interpretation of the Variation in Chinese Contemporary Translation from the Perspective of Skopos Theory [从 Skopos 理论解读中国近代翻译中的变体现象. 北京第二外国 语学院学报]. Journal Beijing Second Foreign Language Institute 6, 24-29.

Zheng, X. 2002. Skopostheories and Advertisement Translation [从 目的性理论看广告翻译.福建农林大学报(哲学社会科学版)]. Journal of Fujian Agriculture Universigy (Social Science Edition) 3, 88-90.

Zhuang, E. 1998. Cultural Difference between China and West \& Cross-Cultrual Communication [东西方文化差异与对外交流. 上海:华东化工学院出版社]. Shanghai: East China Chemical Technology Publishing Company. 